The Egyptian Journal of Hospital Medicine (October 2019) Vol. 77 (1), Page 4815-4819

\title{
Evaluation of The Effect of Combined Intra-Vitreal Ranibizumab Injection and Sub-Tenon Tri-Amcinolone Acetonide Injection in The Management of Diabetic Macular Edema \\ AbdelKader Sayed Abdelkader, Nour eldin abdelhamid, Mohamed Mustafa Bahnassy* \\ Department of Ophthalmology, Faculty of Medicine, Al-Azhar University, Cairo, Egypt \\ Corresponding author: Mohamed Mustafa Bahnassy,email: drmhmdmustafa@yahoo.com
}

\begin{abstract}
Background: to monitor and compare the effect of intravitreal ranibizumab injection alone or with sub-tenon triamcinolone acetonide injection on patients with diabetic macular edema.

Aim of the Work: To assess the effect of combined intravitreal ranibizumab injection, and sub-tenon triamcinolone acetonide injection in the management of diabetic macular edema.

Patients and Methods: Patients with non-proliferative diabetic retinopathy associated with DME (Central macular thickness over $300 \mathrm{um}$ ) which are aimlessly divided into two groups. In group 1, three monthly doses $(0.5 \mathrm{mg})$ of intravitreal ranibizumab are received. In group 2, the anti-VEGF injection was performed 10 days after the sub-tenon steroid injection [triamcinolone acetonide]. All patients' visual acuity, IOP and CMT were followed up for 3 months. Results: The combined treatment showed improved best corrected visual acuity from baseline $0.24 \pm 0.32 \log$ MAR to $0.56 \pm 0.18 \log$ MAR $(\mathrm{p}=0.023)$ which was statistically significant. In addition, there was decreased CMT from baseline $420.1 \pm 112.84$ to $275.73 \pm 90.81$ which was highly statistically significant $(\mathrm{p}<0.001)$. When comparing the combination treatment with the anti-VEGF treatment alone, recovery of BCVA and CMT was statistically significant $(\mathrm{p}=0.041$ and $\mathrm{p}=0.001$, respectively).
\end{abstract}

Conclusion: Steroid addition to the routine anti-VEGF therapy is an effective method of treatment of diabetic macular edema.

Keywords: macular edema $\cdot$ Steroid $\cdot$ Ranibizumab $\cdot$ Diabetic $\cdot$ Combined treatment.

\section{INTRODUCTION}

Diabetic retinopathy (DR), is the commonest reason for drop of vision in the 20-74 aged-population in the developed countries ${ }^{[1]}$. Diabetic macular edema, is the significant reason for vision impairment in patients determined to have diabetic retinopathy ${ }^{[1]}$. In Wisconsin Epidemiologic Study of Diabetic Retinopathy there are over $20 \%$ of type 1 diabetic patients and over $25 \%$ of type 2 insulin-dependent diabetic patients had a degree of vision disability within ten years ${ }^{[2-4]}$.

Despite the pathogenesis of diabetic macular edema (DME) still not clear, it might be caused by some pathological changes as leakages related to retinal vascular abnormalities, localized ischemia, chronic inflammatory processes, and vascular cell degeneration and necrosis ${ }^{[5]}$

The corticosteroids, anti- VEGF and anti-TNFalpha treatments have been appeared to decrease the release of mediators that lead to leukocyte migration and inflammation ${ }^{[6]}$. Studies have tested these antiVEGF medications and demonstrated that the inhibition of vascular endothelial growth factor (VEGF) release have a significant outcome in DME. Therefore, anti-VEGF has become the main factor for the treatment of DME ${ }^{[7-9]}$. However, it is not sufficient for optimal edema control in some cases, which are called persistent macular edema. Some studies demonstrated that the prevalence is over $50 \%{ }^{[10]}$. The persistent DME causes severe disturbance for the retinal architecture that can lead to permanent drop of vision due to unending tissue stress and photoreceptor disruption ${ }^{[11]}$. Accordingly, its treatment is significant and different combination therapies have been gone after for this purpose.

OCT gives more information about the retinal microstructure and measures the retinal thickness with high exactness and reproducibility [12]. OCT morphology patterns in DME may foresee any progression came from the effect of intravitreal antiVEGF injection as a tool in management of DME ${ }^{[13]}$.

\section{MATERIALS AND METHODS}

This prospective study included 30 eyes of patients with non-proliferative diabetic retinopathy related with DME done at Kafr El-Sheikh Ophthalmology Center that were examined and prepared for injection in the operation room under complete aseptic conditions between 01 Decemberr 2018 and 15 May 2019.

Ethical approval:

The study was accepted by the Ethics Board of AlAzhar University. An informed written consent was obtained from every patient before being included in the study.

\section{Study design}

The study will categorize the cases of DME into 2 groups according to method of injection. Group "I" 
included 15 eyes receiving ranibizumab intravitreal injection. Group "II" included 15 eyes receiving combined ranibizumab intra-vitreal injection and subtenon triamcinolone acetonide injection. All patients received a three monthly doses $(0.5 \mathrm{mg})$ of intravitreal ranibizumab and half of them will get subtenon injection of triamcinolone acetonide. Full ophthalmological examination wasl conducted before $\&$ after treatment at month 1 and 3. Examination will include:

1- Best corrected visual acuity (BCVA).

2- Non-contact slit-lamp fundus bio microscopy $(+78 \mathrm{D}$. lens).

3- IOP using applanation tonometer.

4- OCT with measurement the central macular thickness which done for all patients using Topcon 3D OCT 2000.

\section{Inclusion criteria}

- Patients with non-proliferative diabetic retinopathy.

- Non tractional DME.

- Central macular thickness (CMT) over 300 um.

\section{Exclusion criteria}

- Past history of intraocular surgical intervention or intravitreal injection within 6 months.

- Past history of laser photocoagulation within 6 months.

- Macular edema due to other causes in the retina, glaucoma and inflammatory diseases.

- Vitreo-macular traction.

\section{Procedure}

- Pupil was dilated before injection with tropicamide $1 \%$.

- Topical anesthesia [Benoxinate $0.4 \%$ eye drop] was given before the injection.

Disinfection of the lids and lashes with $10 \%$ povidone iodine and the conjunctiva was disinfected with $5 \%$ povidone iodine before intervention.

- $\quad$ The eye was opened with a sterile speculum.

The area of entrance was $3.5 \mathrm{~mm}$ posterior to the limbus in pseudophakic eyes and $4.0 \mathrm{~mm}$ posterior to the limbus in the phakic eyes in the inferior temporal quadrant.

$0.5 \mathrm{mg}(0.05 \mathrm{ml})$ of Leucentis was injected in group 1 , and $4 \mathrm{mg}(0.1 \mathrm{ml})$ of triamcinolone acetonide was injected sub-tenon in group 2.

After injection, fundus assessment was done to check venous pulsation.

Topical antibiotic therapy (ofloxacin) was applied multiple times for 7 days after the injection.

All patients were reexamined the day after injection.

\section{RESULTS}

This study included 21 patients (30 eyes). These eyes were arranged into 2 groups: group A of 15 eyes (11 patients) who got ranibizumab as intravitreal injection and group B of 15 eyes (10 patients) who got a combined injection.

The mean age of our study patients was 53.4 years old (45 to 61) in group A and 55.1 years old (47 to 63) in group B. (table 1)

Table (1): Age distribution

\begin{tabular}{|l|l|l|l|}
\hline Age & Group A & Group B & p-value \\
\cline { 1 - 3 } Mean & 53.4 & 55.1 & 0.568 \\
\cline { 1 - 2 } & 7.9 & 7.8 & \\
\hline
\end{tabular}

Table (2): Sex distribution of the study

\begin{tabular}{|l|l|l|l|}
\hline & Group A & Group B & p-value \\
\hline Male & $6(53.4 \%)$ & $4(40 \%)$ & 0.460 \\
\hline female & $5(46.6 \%)$ & $6(60 \%)$ & \\
\hline
\end{tabular}

Table (3): Comparison between studied groups as regard baseline assessment

\begin{tabular}{|c|c|c|c|c|}
\hline \multicolumn{2}{|c|}{$\begin{array}{l}\text { Baseline } \\
\text { Variables }\end{array}$} & $\begin{array}{l}\text { Leucentis } \\
(\mathrm{N}=15)\end{array}$ & $\begin{array}{l}\text { Combined } \\
(\mathrm{N}=15)\end{array}$ & P-Value \\
\hline \multirow{2}{*}{ BCVA } & Mean & 0.40 & 0.24 & \multirow{2}{*}{0.135} \\
\hline & $\pm \mathrm{SD}$ & 0.30 & 0.32 & \\
\hline \multirow{2}{*}{ IOP } & Mean & 14.0 & 14.7 & \multirow{2}{*}{0.321} \\
\hline & $\pm \mathrm{SD}$ & 1.38 & 1.4 & \\
\hline \multirow{2}{*}{ CMT } & Mean & 385.2 & 420.1 & \multirow{2}{*}{0.246} \\
\hline & $\pm \mathrm{SD}$ & 114.11 & 112.84 & \\
\hline
\end{tabular}




\section{Clinical Results}

Regarding comparison between studied groups 1 month assessment, table (4) demonstrated statistically significant difference as regard 1 month BCVA, IOP and CMT

Table (4): Comparison between studied groups as regards one month assessment of BCVA, IOP and CMT

\begin{tabular}{|c|c|c|c|c|}
\hline \multicolumn{2}{|c|}{$\begin{array}{l}1 \text { month } \\
\text { Variables }\end{array}$} & $\begin{array}{l}\text { Leucentis } \\
(\mathrm{N}=15)\end{array}$ & $\begin{array}{l}\text { Combined } \\
(\mathrm{N}=15)\end{array}$ & P-Value \\
\hline \multirow{2}{*}{ BCVA } & Mean & 0.56 & 0.40 & \multirow{2}{*}{$0.001 * *$} \\
\hline & \pm SD & 0.22 & 0.1 & \\
\hline \multirow{2}{*}{ IOP } & Mean & 14.46 & 16.0 & \multirow{2}{*}{$0.041 * *$} \\
\hline & \pm SD & 1.4 & 1.2 & \\
\hline \multirow{2}{*}{ CMT } & Mean & 305.7 & 316.7 & \multirow{2}{*}{$0.001 * *$} \\
\hline & \pm SD & 92.4 & 110.1 & \\
\hline
\end{tabular}

Comparison between studied groups as regards 3 months assessment showed no statistical significant difference between studied groups concerning BCVA and IOP but there was a statistically significant difference between studied groups as regards CMT (table 5).

Table (5): Comparison between studied groups as regards 3 months assessment of BCVA, IOP and CMT

\begin{tabular}{|c|c|c|c|c|}
\hline \multicolumn{2}{|c|}{$\begin{array}{l}3 \text { month } \\
\text { Variables }\end{array}$} & $\begin{array}{l}\text { Leucentis } \\
(\mathrm{N}=15)\end{array}$ & $\begin{array}{l}\text { Combined } \\
(\mathrm{N}=15)\end{array}$ & P-Value \\
\hline \multirow{2}{*}{ BCVA } & Mean & 0.67 & 0.56 & \multirow{2}{*}{0.156} \\
\hline & \pm SD & 0.18 & 0.18 & \\
\hline \multirow{2}{*}{ IOP } & Mean & 14.7 & 15.4 & \multirow{2}{*}{0.231} \\
\hline & $\pm \mathrm{SD}$ & 0.9 & 1.6 & \\
\hline \multirow{2}{*}{ CMT } & Mean & 281.6 & 275.7 & \multirow{2}{*}{$0.001 * *$} \\
\hline & \pm SD & \begin{tabular}{|l|}
58.8 \\
\end{tabular} & 90.8 & \\
\hline
\end{tabular}

Comparison between BCVA, IOP and CMT follow up in leucentis group showed no statistical significant difference between IOP but there was a statistical significant difference between BCVA and CMT follow up (table 6).

Table (6): Follow up of BCV, IOP and CMT in leucentis group

\begin{tabular}{|c|c|c|c|c|c|}
\hline \multicolumn{2}{|c|}{$7_{\text {Variables }}^{\substack{\text { Leucentis } \\
\text { group }}}$} & $\begin{array}{l}\text { Baseline } \\
(\mathrm{N}=15)\end{array}$ & $\begin{array}{l}1 \text { month } \\
(\mathrm{N}=15)\end{array}$ & $\begin{array}{l}3 \text { month } \\
(\mathrm{N}=15)\end{array}$ & P-Value \\
\hline \multirow{2}{*}{ BCVA } & Mean & 0.40 & 0.56 & 0.67 & \multirow{2}{*}{$0.041 *$} \\
\hline & \pm SD & 0.30 & 0.22 & 0.18 & \\
\hline \multirow{2}{*}{ IOP } & Mean & 14.0 & 14.46 & 14.7 & \multirow{2}{*}{0.230} \\
\hline & \pm SD & 1.38 & 1.4 & 0.9 & \\
\hline \multirow{2}{*}{ CMT } & Mean & 385.20 & 305.7 & 281.6 & \multirow{2}{*}{$0.001 *$} \\
\hline & $\pm \mathrm{SD}$ & 114.11 & 92.4 & 58.8 & \\
\hline
\end{tabular}

Comparison between BCVA, IOP and CMT follow up in combined group showed highly statistical significant difference between CMT follow up and there was statistically significant difference between BCVA and IOP follow up (table 7). 
Table (7): Follow up of BCV, IOP and CMT in combined group

\begin{tabular}{|c|c|c|c|c|c|}
\hline \multicolumn{2}{|c|}{$\begin{array}{cc}\text { Combined } \\
\text { Variables }\end{array}$} & $\begin{array}{l}\text { Baseline } \\
(\mathrm{N}=15)\end{array}$ & $\begin{array}{l}1 \text { month } \\
(\mathrm{N}=15)\end{array}$ & $\begin{array}{l}3 \text { month } \\
(\mathrm{N}=15)\end{array}$ & P-Value \\
\hline \multirow{2}{*}{ BCVA } & Mean & 0.24 & 0.40 & 0.56 & \multirow{2}{*}{ 0.023* } \\
\hline & \pm SD & 0.32 & 0.10 & 0.18 & \\
\hline \multirow{2}{*}{ IOP } & Mean & 14.7 & 16.0 & 15.4 & \multirow{2}{*}{$0.001 *$} \\
\hline & \pm SD & 1.4 & 1.2 & 1.6 & \\
\hline \multirow{2}{*}{ CMT } & Mean & 420.1 & 316.7 & 275.73 & \multirow{2}{*}{$<0.001 * *$} \\
\hline & \pm SD & 112.84 & 110.1 & 90.81 & \\
\hline
\end{tabular}

\section{DISCUSSION}

Diabetic macular edema (DME) is the fundamental driver of dynamic lessening of vision in diabetic retinopathy patients. Numerous agents are utilized in the treatment of DME, including non-steroid (anti-VEGF) and steroid (triamcinolone, dexamethasone implant, etc.) injections ${ }^{[14-17]}$.

While the VEGF release is considered the principle factor in DME etiology, it is believed that many proinflammatory cytokines play a role in DME advancement in cases that doesn't react well to frequent anti-VEGF treatments. This pushed us to focus on steroid therapy. The corticosteroid injections declined macular edema through inhibition of leukocytes release, VEGF, prostaglandins, and other provocative inflammatory cytokines and providing stability for the capillary wall [18].

In the present study, we found that combination treatment improved BCVA from baseline $0.24 \pm 0.32 \mathrm{log}$ MAR to $0.56 \pm 0.18 \log$ MAR and reduced CMT from baseline $420.1 \pm 112.84$ to $275.73 \pm 90.811 \mathrm{~m}$. When comparing combination treatment with solely anti-VEGF treatment, recovery of BCVA and CMT was statistically significant. Likewise there was no critical difference between the two groups in terms of IOP increase before injection and at 3 months follow up. However, there was significant difference between the two groups after 1 month follow up.

Despite, dexamethasone implant utilization on wide range, may cause complications on the long run as shown in a randomized study, $0.7 \mathrm{mg}$ dexamethasone implant and anti-VEGF agent (bevacizumab) were compared in patients with diabetic macular edema. An improvement of visual acuity was observed in $40 \%$ of the cases in the bevacizumab group and also the same percentage of the patients in the dexamethasone group. In addition, there was no diminution in visual acuity in any of the cases in the bevacizumab group, while in the dexamethasone group there was a decrease in visual acuity due to cataract formation in $11 \%$ of the cases ${ }^{[19]}$.
In that review, the incidence of cataracts in dexamethasone implant group was $70.3 \%$ while In the present study, a single sub-tenon steroid was administered in group II and no cataract formation was observed in any of our patient.

The improvement in BCVA was significantly observed in group II and so there was statistically significant increase noted in group I $(\mathrm{p}=0.023, \mathrm{p}=$ 0.041, respectively).

In the present review, there were highly significant changes observed in CMT in the sub-tenon steroid administered combination group, compared to changes in CMT with anti-VEGF injection only.

As regards the effect of ranibizumab on the intraocular pressure, there was no statistically significant difference after the three injections. In a study by Antonio et al. ${ }^{[20]}$, there was no difference in intraocular pressure noted throughout the study and no significant change in intraocular pressure was seen at any visit compared with baseline. In that study (Antonio et al. study) 48 patients (63 eyes) with center-involved DME were included where the ranibizumab treatment reduced the CMT from $421 \mu \mathrm{m}$ to a level of $328 \mu \mathrm{m}$ after one month of injection, and to a level of $309 \mu \mathrm{m}$ after three months of injection. The results of this study are consistent with the data from other studies which goes in accordance with Elman et al. ${ }^{[21]}$ results, which demonstrated that no apparent association between intravitreal ranibizumab injection and the rise in intraocular pressure and are in contrast to some studies as Tseng et al. ${ }^{[22]}$ that had suggested such an association.

On the other side there was statistical difference in IOP that was observed in combined group $(p=0.001)$ where the maximum increase was observed after 1 month of injection. In Elman et al. ${ }^{\text {[21] }}$ study, there was a huge ascent in intraocular pressure (IOP) that was seen in $38 \%$ of the patients in the intravitreal tri-amcinolone group, while this was seen distinictly in $5 \%$ of the cases in the intravitreal ranibzumab group.

In recent years, the intravitreal steroid 
(dexamethasone implants) are used on wide range in treatment of diabetic macular edema which was resistant to anti-VEGF treatment. In a study by Dutra Medeiros et $\boldsymbol{a l}^{[23]}$, it was discovered that extreme efficacy was seen in the third month during the 6-month follow-up period and there was a lessening in central macular thickness (CM) in $37 \%$ with a single injection and a mean improvement of $0.44 \pm 0.27 \log$ MAR in BCVA. That review assessed only the impact of steroids only and not the combined effect as in our study.

\section{CONCLUSION}

In the present study, it was determined that in addition to its functional advantages, the anti-VEGF treatment combined with sub-tenon steroid injection minimizes the number of recurrent injections when compared to anti-VEGF treatment alone, so the cost will be cheaper.

\section{REFERENCES}

1. Williams GA (2012): Diabetic macular edema. In: Bandello F, Querques G (eds) ESASO course series, vol. 1. Medical retina. Karger, Basel, Pp: 99-104

2. Klein R, Klein BEK, Moss SE, Davis MD, DeMets DL (1984): The Wisconsin Epidemiologic Study of Diabetic Retinopathy II: prevalence and risk of diabetic retinopathy when age at diagnosis is less than 30 years. Arch Ophthalmol., 102: 520-526

3. Klein R, Klein BEK, Moss SE, Davis MD, DeMets DL (1984): The Wisconsin Epidemiologic Study of Diabetic Retinopathy III: prevalence and risk of diabetic retinopathy when age at diagnosis is 30 and more years. Arch Ophthalmol., 102: 527-532

4. Klein R, Klein BEK, Moss SE, Cruickshanks KJ (1995): The Wisconsin Epidemiologic Study of Diabetic Retinopathy. XV: the long-term incidence of macular edema. Ophthalmology, 102: 716

5. Adamis AP (2002): Is diabetic retinopathy an inflammatory disease? Br J Opthalmol., 86: 363-365

6. McGhee CN (1992): Pharmacokinetics of ophthalmic corticosteroids. Br J Ophthalmol., 76: 681-684

7. Brown DM, Nguyen QD, Marcus DM et al. (2013): Long- terms outcomes of ranibizumab therapy for diabetic macular edema: the 36-month results from two phase III trials: RI'SE and RIDE. Ophthalmology, 120: 2013-2022

8. Diabetic Retinopathy Clinical Research Network, Wells JA, Glassman AR, Ayala AR et al (2015) Aflibercept, bevacizumab or ranibizumab for diabetic macular edema. N Engl J Med., 372: 1193-1203

9. Do DV, Nguyen QD, Boyer D et al. (2012): One-year out- comes of the da VINCI study of VEGF trap-eye in eyes with diabetic macular edema. Ophthalmology, 119: 1658-1665

10. Elman MJ, Bressler NM, Qin H et al. (2011) Expanded 2-year follow-up of ranibizumab plus prompt or deferred laser or triamcinolone plus prompt laser for diabetic mac- ular edema. Ophthalmology, 118: 609-614.

11. Uji A, Murakami T, Nishijima $K$ et al. (2012) Association between hyperreflective foci in the outer retina, status of photoreceptor layer, and visual acuity in diabetic macular edema. Am J Ophthalmol., 153: 710-717.

12. Diabetic Retinopathy Clinical Research Network (2007): Reproducibility of macular thickness and volume using Zeiss optical coherence tomography in patients with diabetic macular edema. Ophthalmology, 114: 1520-1525.

13. Haider R, Ahmed A, Essam A (2014): Improvement of visual acuity based on optical coherence tomography patterns following intravitreal bevacizumab treatment in patients with diabetic macular edema. International Journal of Ophthalmology, 7:2.

14. Dutra Medeiros M, Postorino M, Navarro R, GarciaArum'ı J, Mateo C, Corco'stegui B (2014): Dexamethasone intravitreal implant for treatment of patients with persistent diabetic macular edema. Ophthalmologica, 231 (3): 141-146

15. Pacella F, Ferraresi AF, Turchetti $P$, Lenzi T, Giustolisi $R$, Bottone A, Fameli V, Romano MR, Pacella E (2016): Intravitreal injection of Ozurdex(®) implant in patients with persistent diabetic macular edema, with six-month follow- up. Ophthalmol Eye Dis., 8: 11-16

16. Blinder KJ, Dugel PU, Chen S, Jumper JM, Walt JG, Hollander DA, Scott LC (2017): Anti-VEGF treatment of diabetic macular edema in clinical practice: effectiveness and patterns of use (ECHO Study Report 1). Clin Ophthalmol., 11: 393-401

17. Shin YU, Hong EH, Lim HW, Kang MH, Seong M, Cho H (2017): Quantitative evaluation of hard exudates in diabetic macular edema after short-term intravitreal triamcinolone, dexamethasone implant or bevacizumab injections. BMC Ophthalmol., 17 (1):182

18. Tamura H, Miyamoto K, Kiryu J et al. (2005) Intravitreal injection of corticosteroid attenuates leukostasis and vas- cular leakage in experimental diabetic retina. Invest Oph- thalmol Vis Sci., 46 (4): 1440-1444.

19. Gillies MC, Lim LL, Campain A et al. (2014) A randomized clinical trial of intravitreal bevacizumab versus intravitreal dexamethasone for diabetic macular edema: the BEV- ORDEX study. Ophthalmology, 121: 2473-2481.

20. Antonio brunno Nepomuceno, Rodrigo Jorge et al. (2013): A prospective randomized trial of intravitreal bevacizumab versus ranibizumab for the management of diabetic macular edema. American journal of ophthalmology, 156: 502-510.

21. Elman MJ, Aiello LP, Beck RW, Bressler NM, Bressler SB, Edwards AR et al. (2010): Diabetic retinopathy clinical research network, Randomized trial evaluating ranibizumab plus prompt or deferred laser or triamcinolone plus prompt laser for diabetic macular edema. Ophthalmology, 117: 10641077.

22. Tseng JJ, vance SK, Della torre KE et al. (2012): Sustained increased intraocular pressure related to intravitreal antivascular endothelial growth factor therapy for neovascular age related macular degeneration .J Glucoma, 21: 241-247.

23. Dutra Medeiros M, Postorino M, Navarro R, GarciaArum'ı J, Mateo C, Corco'stegui B (2014): Dexamethasone intrav- itreal implant for treatment of patients with persistent dia- betic macular edema. Ophthalmologica 231 (3): 141-146. 